\title{
Perfil do aluno de psicopedagogia
}

\author{
Psych-education major students' profile
}

Maria Regina Peres*

Faculdades Network

Resumo Os cursos de pós-graduação lato sensu, dentre eles o de psicopedagogia, têm apresentado uma crescente demanda nos últimos anos. Pouco se sabe sobre quem são os profissionais que procuram esses cursos. Realizamos um estudo com 251 alunos ingressantes no curso de psicopedagogia, durante os anos de 2005 a 2012, pretendendo conhecer o perfil destes alunos e também os seus objetivos. Utilizamos um questionário de sondagem sobre a formação inicial do aluno, a sua atuação, experiência e futuras intenções. Os resultados indicaram que a maioria dos alunos são pedagogos que atuam como professores e objetivam alcançar melhorias na prática profissional. Concluimos que estes profissionais estão em busca de metodologias alternativas de trabalho que possam se reverter em melhorias educacionais.

PAlaVRaS-ChaVe: Educação, Prática profissional, Metodologias.

Abstract Among our post-graduate courses, Psych-Education demand has grown in the last few years. Little is known about the professionals who seek these courses. A research was done on a group of 251 new students in the Psych-Education Graduate course from 2005 to 2012, with the expectation of understanding the students profile and objectives. A questionnaire was provided to discover their major area of study in their Bachelor's degree, work experience, and future aspirations. The results indicated that most students were Education majors who work now in the teaching profession with the objective of obtaining more professional training. It was concluded that these professionals are seeking alternative methods of teaching that will enhance the educational field.

KEYWORDS: Education, Professional training, Methods. 
Historicamente, segundo Masini (2000), temos que as primeiras ideias referentes a psicopedagogia se originaram na França, por volta da década de quarenta. Nessa época, a Europa se mobilizava em estudar as influências de origem orgânica responsáveis pelo insucesso escolar. Dessa forma, unidos em torno de objetivos comuns, médicos, psicólogos e educadores passaram a desenvolver um trabalho de pesquisa conjunto. Estes estudos visavam diagnosticar os possíveis problemas de aprendizagem por meio de intervenções orgânicas e pedagógicas. Ao final dos anos sessenta, a psicopedagogia sofre um novo redimensionamento na França. Este fato impulsionou o desenvolvimento de novas pesquisas e experiências e, a própria França torna-se um dos primeiros países a inovar e a investir na modalidade psicopedagógica clinica e institucional (BOSSA, 2011).

Sem a pretensão de apresentar um resgate histórico da psicopedagogia, estamos, aqui, destacando alguns referenciais que marcaram o seu crescimento e desenvolvimento. Assim, com o passar do tempo, a psicopedagogia despertou a atenção de vários países que preocupados com os altos índices de insucessos escolares passaram a buscar novas alternativas de trabalho. Dentre esses países, se destaca a Argentina, um dos primeiros, segundo Visca (2003), a propor um curso de graduação em psicopedagogia, junto à Universidade de Buenos Aires. Esse curso de graduação, segundo Andrade (2004), foi criado em 1956, visando o aperfeiçoamento docente. A Argentina também foi o primeiro país que reconheceu a Psicopedagogia como profissão além de investir na criação de "Centros Psicopedagógicos" oficiais e gratuitos. Com isto, atualmente a psicopedagogia tem ocupado um lugar de destaque junto às áreas da educação e da saúde com o objetivo de desenvolver intervenções visando propor alternativas para o insucesso escolar.

No Brasil, segundo Scoz e Mendes (1987), a primeira experiência psicopedagógica teria ocorrido em 1954, no Rio Grande do Sul, por meio do "Curso de Orientação Psicopedagógica”. O curso priorizava a formação para o atendimento de crianças com necessidades educacionais especiais.

Em 1958, segundo Masini (2000), temos outro marco histórico muito significativo para a psicopedagogia. A na criação do Serviço de Orientação Psicopedagógica (SOPP) da "Escola Guatemala", na então Guanabara. Esta era uma escola experimental do Instituto de Estudos e Pesquisas Educacionais (INEP) do Ministério da Educação e Cultura (MEC), que tinha por objetivos a melhoria da relação professor aluno, a criação de um clima mais receptivo para o aprendiz, considerando a sua "bagagem cultural". Durante os anos 60 e 70, a psicopedagogia amplia seu campo de estudo, em nosso país, passando a considerar tanto o aluno como o professor nas questões ligadas ao insucesso escolar.

Essas experiências impulsionam, em 1980, a criação da "Associação de Psicopedagogos de São Paulo" que, segundo Scoz (2011), visava ampliar conhecimentos sobre a área em questão além da troca de experiências enfocando os problemas de aprendizagem. Com o crescente avanço na atuação psicopedagógica em 1988 a "Associação de Psicopedagogos de São Paulo" se transforma na "Associação Brasileira de Psicopedagogia", passando a promover diversas atividades como cursos, palestras, conferências. Isto contribui para impulsionar o crescimento da psicopedagogia no Brasil. 
A formação do psicopedagogo no Brasil segue, atualmente, as determinações da atual Lei de Diretrizes e Bases da Educação Nacional (LDB) n. ${ }^{\circ}$ 9394, aprovada em 20 de dezembro de 1996 (Secretaria de Estado da Educação de São Paulo, 1996). Esta legislação determina, por meio do artigo 64, que a formação de profissionais da educação seja feita em cursos de graduação ou pós-graduação. Assim, esta formação segundo Serrano (2001), esta ocorrendo, de modo geral, em cursos de pósgraduação lato sensu, vinculados as instituições de ensino que atendem as exigências legais determinadas pelo Conselho Nacional de Educação.

Assim sendo, a formação do psicopedagogo no Brasil tem sido alvo dos estudos Bossa (2011), Massini (2000), no que se refere especialmente à questão da formação e da identidade deste profissional. Essas pesquisadoras destacam que a questão da formação inicial e continuada do psicopedagogo é extremamente relevante, pois elas delinearão a construção da identidade desse profissional.

Portanto, se torna fundamental que não tratemos este tema de forma periférica, mas que investiguemos algumas questões reais e legitimas que nos permitam ampliar nossos conhecimentos sobre: quem são os profissionais que têm procurado esses cursos de psicopedagogia? Quais suas necessidades? Quais são os seus objetivos?

Ao ampliarmos nossas reflexões para além da psicopedagogia e considerarmos a importância da formação continuada para todos os profissionais, temos em Batista (2000) que a histórica demanda que os cursos de especialização vêm conseguindo, na cultura educacional brasileira é decorrente da crescente busca pela continuidade de estudos. Os alunos concluintes de cursos de graduação, cada vez mais, têm procurado se inserir em programas de pós-graduação lato sensu. Em princípio, seria relativamente fácil se identificar algumas das crenças e razões que parecem justificar este fenômeno. Dentre elas, destacamos a alta competitividade do mercado de trabalho, que incentiva a crescente busca por novas especializações; a necessidade de complementar os estudos com conhecimentos não previstos ou abordados nos cursos de graduação; a crença de que o sucesso pessoal e profissional está diretamente relacionado com os cursos de pós-graduação; a questão econômica, no sentido de se ampliar os rendimentos em função da nova titulação e até mesmo a estabilidade profissional dependendo da continuidade de estudos.

Associadas a estas ideias, temos que, nos últimos anos, as diferentes instituições sociais estudam o fenômeno das mudanças sociais globais. A educação não esta alheia às consequências deste fenômeno (Dale, 2004). Desta forma, as mudanças sociais indicam e, ao mesmo tempo impulsionam, a constante necessidade da continuidade de estudos visando especialmente o estabelecimento de relações e a aplicação de questões teóricas na vida prática.

Neste sentido, Dias e Lopes (2003), enfatizam que as transformações curriculares, as avaliações de desempenhos, as promoções por mérito, os conceitos de produtividade, eficiência e eficácia, impulsionam a busca pela continuidade de estudos. Isso pode gerar o imediatismo onde se multiplicam os cursos e as vagas, vários projetos são abandonados ou transformados, improvisam-se os prédios, os equipamentos e até mesmo os professores, sem que haja preocupação com a qualidade. 
Ao abordar o imediatismo educacional, Brzezinski (2008) destaca que a formação baseada no aprendizado imediatista leva a um 'praticismo' simplista, distante do verdadeiro significado de educação. A obtenção de melhorias educacionais também esta relacionada com a qualidade da formação docente. Segundo Demo (2001), esta relação deverá se constituir em uma meta a ser alcançada tanto pelas instituições como pelos docentes. Isso irá se reverter em melhorias nos projetos pedagógicos e consequentemente no processo de ensino e aprendizagem.

O mundo contemporâneo, como enfatiza Libâneo (2011) pede ações pedagógicas mais definidas, implicando em uma constante atualização teórica e profissional, muito além da apresentada, hoje, nos cursos de formação. Isto contribui para o crescimento da oferta de cursos de pós-graduação lato sensu que especialmente pela sua curta duração, vêm atraindo a muitos.

A necessidade de continuidade de estudos também foi alvo das pesquisas de Perrenoud (2000), ao destacar que toda e qualquer formação inicial merece ser periodicamente repensada em função da evolução das condições do trabalho, das exigências do mercado profissional e do avanço tecnológico. Este pesquisador ainda acrescenta que a renovação das formações iniciais é parte integrante de uma transformação mais fundamental da profissão. Isso consolida a importância de se ampliar a formação inicial enfatizando que, em um futuro próximo, esta formação não conseguirá atender os domínios exigidos a um profissional consciente, atualizado e comprometido com o processo educacional. Isto irá se constituir em um fator limitante ao exercício profissional.

Ainda, sobre a importância da continuidade de estudos temos as pesquisas de Peres (1998), Britto (1999), Gatti (2003), que destacam a crescente busca por cursos de pós-graduação lato sensu, visando a obtenção de melhorias educacionais que se revertam em melhorias diretas no processo de ensino e aprendizagem.

Diante destes referenciais, temos que um dos cursos de pós-graduação lato sensu o qual tem apresentado as mais altas demandas, atualmente na área de educação, tem sido o curso de psicopedagogia. Esse curso, segundo Bossa (2011), tem contribuído decisivamente na relação formação, atualização e atuação profissional, uma vez que a psicopedagogia se ocupa da aprendizagem humana, avançando e interagindo nos limites da psicologia e da pedagogia.

Assim, conforme os estudos de Kolyniak (2001), um dos maiores objetivos da psicopedagogia é o de diagnosticar e prevenir problemas de aprendizagem. Neste sentido ela vai crescendo como uma área de conhecimento destinada a preencher possíveis lacunas entre a formação, a atualização e a atuação profissional.

Com isto, tendo como referencial a histórica expansão dos cursos de pósgraduação lato sensu e, especialmente neste momento de grande demanda sobre está área de conhecimento, a psicopedagogia, entendemos como de essencial relevância investigarmos quem são os profissionais que têm procurado esses cursos, quais são suas necessidades e seus objetivos. 
A partir destes referenciais, propusemos um trabalho de investigação junto aos alunos de psicopedagogia, com o objetivo de traçar o perfil do ingressante em um dos cursos de maior demanda atualmente. Entendemos ser de fundamental importância conhecer estes alunos no sentido de que os cursos, nesta área de conhecimento, poderiam melhor organizar os seus projetos pedagógicos em função dos interesses e necessidades apresentados.

\section{Método}

\section{Participantes}

Nesta pesquisa participaram duzentos e cinquenta e um alunos, com idades variando entre acima de vinte anos a superior a cinquenta anos. $O$ universo da pesquisa se constituiu de alunos ingressantes em cursos de psicopedagogia de duas faculdade do interior do estado de São Paulo, durante o período de 2005 a 2012.

\section{Material}

O material utilizado foi um questionário com perguntas abertas. Nele foi considerado a formação original do aluno, a instituição de formação, a atuação profissional, o local de atuação, a experiência profissional e a idade. Na sequência, as questões foram mais específicas, enfatizando a opção pelo curso, a concepção sobre a área de estudo e as expectativas ao iniciar o curso de psicopedagogia.

\section{Procedimento}

A aplicação do questionário, composto de perguntas abertas, ocorreu em sala de aula e de forma coletiva. As questões foram propostas, sem que houvesse nenhuma espécie de intervenção.

Ao elaborarmos os questionamentos, intencionalmente, propusemos duas questões complementares que se referiram à procura pelo curso e à expectativa em relação ao mesmo. Estas questões tiveram por objetivo obter elementos mais significativos para que pudéssemos analisar a coerência e a significação das respostas obtidas.

A seguir, os dados foram tabulados e serão apresentados em forma de porcentagem. Diante disso, analisaremos os resultados obtidos junto aos participantes da pesquisa enfocando a construção do perfil do aluno de psicopedagogia.

\section{Resultados}

Os resultados apresentados consideraram as informações gerais relativas a: idade, formação, instituição de origem do aluno, local de atuação e experiência profissional. $\mathrm{Na}$ sequência, procuramos abrir três frentes de investigação para que juntamente com os dados iniciais, elas nos auxiliassem na composição do perfil do aluno de psicopedagogia. Para isto, consideramos os dados referentes a opção de escolha pelo curso, concepção sobre a área de conhecimento e expectativas do aluno ao iniciar o curso em questão. 
Tendo como referencial os dados obtidos e os objetivos propostos, organizamos e apresentaremos a seguir os resultados dos anos de 2005 a 2012.

Assim, do total de duzentos e cinquenta e um alunos pesquisados, cento e oitenta e seis são pedagogos, vinte e um são psicólogos, um é fonoaudiólogo e quarenta e três são oriundos de cursos de licenciatura - Matemática, Letras, Biologia, Geografia e Educação Física. Deste total, aproximadamente 78\% são formados em instituições particulares de ensino.

Os resultados obtidos revelam que a atuação profissional predominante é a de professor de instituição pública de ensino, seguida pela de profissionais que desenvolvem atividades relacionadas à educação, ou seja, por profissionais que estão atuando em instituições de ensino, desempenhando funções de diretor, coordenador e orientador educacional. Uma exceção, temos, no ano de 2007, quando registramos um significativo crescimento de profissionais atuando em atividades relacionadas à educação, aproximadamente $52 \%$ dos profissionais pesquisados atuavam como diretores, coordenadores, orientadores e aproximadamente $41 \%$ atuavam como professores.

Em relação ao total de alunos pesquisados, constatamos a existência de procura pelo curso tanto por parte de alunos mais jovens e em início de carreira, como por alunos mais experientes com, por exemplo, acima de trinta anos de profissão. Observase que, no ano de 2008, tivemos a constituição de um grupo de alunos mais jovens do que nos demais anos. Fato contrário ocorreu, nos anos de 2009, 2011 e 2012, quando os grupos constituídos foram de alunos mais experientes. Diante disso, podemos afirmar que o interesse pela formação continuada, nesse caso, vem atraído tanto a jovens profissionais em início de carreira como a profissionais mais experientes.

Ao analisarmos os dados obtidos constatamos, com exceção dos anos de 2009 e 2012, a predominância de pedagogos que atuam como professores em instituições públicas de ensino. Esta foi uma característica que se revelou constante durante os anos de investigação. Isto, certamente, deveria se constituir em um referencial norteador para a estruturação dos projetos pedagógicos das instituições que, ao oferecerem cursos de psicopedagogia, deveriam, dentre outras questões, considerar a realidade e os interesses da população alvo.

No que se refere ao local de atuação dos participantes da pesquisa, constatamos que além dos que atuam em instituições, temos a existência de um número significativo de alunos que categorizamos como outros. Estes alunos atuam em clinicas, em assessorias pedagógicas, como autônomos, no comércio e em bancos. Ao compararmos os anos em que esta investigação foi desenvolvida, registramos, no ano de 2009, um significativo crescimento dessa categoria que apresentou aproximadamente $36 \%$ do total de alunos.

$\mathrm{Na}$ continuidade, para nos auxiliar na composição do perfil do aluno de psicopedagogia, apresentamos e analisamos os objetivos que os levaram a procurar o curso. Os dados obtidos foram tabulados considerando os objetivos de maior frequência de respostas. Os resultados obtidos revelam que noventa e quatro alunos, ou seja, aproximadamente $37 \%$, estão frequentando o curso de psicopedagogia em busca de subsídios que se revertam em melhorias da prática profissional. Na sequencia, oitenta alunos, ou seja, aproximadamente $32 \%$, vieram em busca de continuidade de estudos e cinquenta e dois alunos, ou seja, aproximadamente $21 \%$ vieram em busca de atua- 
lização pedagógica. Sobre este mesmo objetivo, temos uma significativa variação se compararmos os dados obtidos nos anos de 2008 e 2012. Em 2008, aproximadamente $6 \%$ dos participantes da pesquisa visavam a atualização pedagógica. Em 2012, ocorreu um aumento significativo desta intenção, sendo que aproximadamente $30 \%$ dos pesquisados expressaram esse objetivo.

$\mathrm{Na}$ categoria outros, temos aproximadamente $10 \%$ dos participantes, ou seja, 25 alunos que não expressaram clareza de seus objetivos, pois utilizaram respostas como: "achar o curso interessante", "gostar de crianças", "indicação de familiares", "falta de opção". Consideramos estas respostas um tanto quanto ingênuas para profissionais já graduados e inseridos no mercado de trabalho.

Ao analisarmos os três objetivos de maior frequência de respostas, constatamos a necessidade de articular os conhecimentos anteriores a novos conhecimentos, a preocupação com a aplicabilidade de conhecimentos na prática profissional, a valorização da obtenção de subsídios que se revertam em reais melhorias no cotidiano da ação educativa. Essas inquietações segundo Kolyniak (2001) demonstram os interesses e necessidades dos participantes da pesquisa, e busca possibilidades para minimizar as possíveis situações de insucessos escolares.

A seguir, outra questão, objeto de pesquisa, se relacionou à concepção dos participantes sobre a área de psicopedagogia.

Os dados obtidos apontaram que oitenta e quatro alunos, ou seja, aproximadamente $34 \%$ dos participantes da pesquisa concebem a psicopedagogia como uma área ou campo que estuda as dificuldades de aprendizagem. A seguir, temos sessenta e oito alunos, ou seja, aproximadamente $27 \%$ que concebem a psicopedagogia como a união da psicologia com a pedagogia.

Estas ideias se aproximam da concepção usualmente defendida por vários psicopedagogos, dentre eles por Castanho (2002), Luque (2006), Gabriel e Yaegashi (2013), que concebem a psicopedagogia como uma área de conhecimento e de atuação interdisciplinar, cujo objeto de estudo é o processo de aprendizagem e suas interações sociais, tendo como referenciais teóricos duas ciências, a Psicologia e a Pedagogia. Portanto, esses alunos, apesar de não expressarem detalhes sobre a concepção apresentada, revelaram compreender o objeto de estudo da psicopedagogia. Mesmo os cinquenta $\mathrm{e}$ seis alunos, ou seja, aproximadamente $22 \%$ do total, que relacionaram a psicopedagogia com o estudo dos distúrbios de aprendizagem, apresentaram ideias pertinentes à área de estudo em questão, uma vez que o psicopedagogo contribui visando minimizar o insucesso escolar.

Por outro lado, quarenta e três alunos, ou seja, aproximadamente $17 \%$ dos participantes da pesquisa, apresentaram concepções muito distantes da área de estudo da psicopedagogia. Estes alunos concebem a psicopedagogia como: "estudo aprofundado da pedagogia", "campo de atuação do psicólogo escolar", "métodos de ensino", "espécie de atendimento a crianças com deficiência", "técnica para atendimento à alunos". Neste caso, ou eles se expressaram mal, ou realmente não tem ideia do campo de atuação do psicopedagogo. Este dado se revela como altamente preocupante uma vez que os pesquisados se constituem em futuros psicopedagogos. 
A última etapa desta investigação se relacionou às expectativas dos participantes da pesquisa ao iniciarem o curso de psicopedagogia. Esta questão intencionalmente está vinculada à questão referente aos objetivos apresentados para a procura pelo curso. Tivemos, com isto, o objetivo de analisar a coerência das respostas obtidas.

Os resultados indicaram que: cento e vinte alunos, ou seja, aproximadamente $48 \%$ dos participantes almejam a obtenção de melhorias na prática profissional; setenta alunos, aproximadamente $28 \%$ do total pretendem ampliar os conhecimentos da graduação; vinte e sete alunos, aproximadamente $11 \%$, visam a troca de experiências profissionais e quinze alunos, aproximadamente $6 \%$, pretendem continuar os estudos visando o curso de mestrado. Por outro lado, temos dezenove alunos, ou seja, aproximadamente $8 \%$ do total de participantes que foram considerados em uma categoria à parte, por apresentarem expectativas variadas. Nesta categoria foram consideradas as seguintes respostas: "obter titulação visando a ascensão profissional", "abrir clinica para atendimento", "fazer novos amigos", "voltar a estudar", "conhecer novas bibliografias".

Durante os anos de 2005 a 2012, constata-se a regularidade dos dados obtidos em relação às expectativas de melhorias na prática profissional e pela busca em ampliar os conhecimentos iniciais. Esta regularidade não está presente na categoria de respostas que considera a troca de experiências, pois, a mesma variou de aproximadamente $19 \%$ de alunos no ano de 2010 para aproximadamente $4 \%$ de alunos no ano de 2012. Fato semelhante temos no que se refere a continuidade de estudos pois, no ano de 2009 , aproximadamente $3 \%$ dos alunos destacaram esta expectativa, ao contrário do ano de 2012, quando aproximadamente $13 \%$ dos alunos destacaram a mesma. Entretanto, ponderamos se a ampliação de conhecimentos não estaria relacionada ou mesmo não seria decorrente da continuidade de estudos. Nesse sentido, estas expectativas poderiam ser entendidas como complementares.

Ao compararmos estes resultados com os dados obtidos anteriormente, no qual consideramos os objetivos dos pesquisados, temos que noventa e quatro dos participantes pretendem obter subsídios visando melhorias na prática profissional, oitenta alunos visam a continuidade de estudos e cinquenta e dois alunos a atualização pedagógica. Ao confrontarmos os dados, podemos perceber a coerência entre os objetivos e expectativas em relação ao curso de psicopedagogia. Isso reflete claramente o comprometimento dos pesquisados com a área em questão.

Este fato, segundo Veiga (2003), deverá também demandar em compromisso por parte das instituições de ensino que por meio da elaboração de seus projetos pedagógicos, deverão se sensibilizar atendendo aos interesses e necessidades de seus alunos. Com isso, os projetos institucionais se constituirão em um processo de construção interna, considerando os diversos segmentos da escola como a equipe técnica, os docentes, os discentes, e demais participantes da vida escolar. Estes projetos também devem atender a comunidade escolar. A partir disto se ampliaria a formação do aluno por meio do seu comprometimento com a integração comunidade e escola.

Diante disso, se constata a necessidade do educador articular conhecimentos teóricos, certamente advindos da sua formação inicial, com os conhecimentos práticos, construídos, re(construídos), re(significados) na sua formação continuada. 
Dessa forma, por meio da possibilidade dos "vários olhares", para a realidade da prática cotidiana, espera-se que o profissional tenha a oportunidade de melhor interpretar e inferir sobre a mesma conquistando a tão desejada melhoria educacional.

\section{Considerações finais}

Com este estudo, tivemos por objetivo traçar o perfil do aluno de psicopedagogia, tendo como referenciais suas necessidades e seus objetivos. Assim, após a aplicação do instrumento proposto, durante os oito anos de investigação e, considerando as variações encontradas e já apontadas, concluímos, com base nos dados obtidos, que: atualmente, o aluno de psicopedagogia, em sua maioria, possui graduação em pedagogia sendo proveniente de instituições particulares de ensino. $\mathrm{O}$ mesmo se encontra atuando como professor em instituições públicas de ensino.

Este estudo também revela que o aluno que tem procurado o curso em questão, no geral, vem em busca de subsídios que se revertam em melhorias na prática profissional. Isso demonstra uma pré-disposição em refletir a própria prática e buscar alternativas concretas que possam se transformar em melhorias educacionais. Como no geral, a quase totalidade dos pesquisados está atuando em sala de aula, como docente, podemos concluir que os mesmos estão em busca de metodologias alternativas de trabalho. O que segundo Rubinstein (2004) tem sido uma tendência entre os profissionais que procuram os cursos de psicopedagogia. Ela aponta que estes profissionais apresentam-se atentos às possíveis dificuldades de seus alunos e buscam propostas metodológicas diferenciadas que possam prevenir o insucesso escolar.

A partir desta perspectiva, o psicopedagogo tende a se tornar um profissional reflexivo, ativo, que constrói e re(constrói) a sua prática tendo como referenciais os aspectos teóricos, os seus objetivos e as suas ações. Estas características na concepção de Azzi e Sadalla (2002) contribuem para a compreensão e para a transformação das práticas pedagógicas uma vez que auxiliam o professor na re(elaboração) e re(significação) da própria prática.

Por outro lado, ao considerarmos os resultados deste estudo, e os desafios presentes na formação do psicopedagogo, novos questionamentos merecem ser desencadeados. Dentre eles, destacamos algumas indagações que, frente a este estudo, consideramos altamente significativas como: Qual o compromisso dos cursos de psicopedagogia diante dos objetivos e necessidades dos alunos? Até que ponto os alunos que procuram a psicopedagogia não estão sendo influenciados por modismos e crenças de que este curso poderia responder a todas as situações de insucessos escolares? Como fica a prática dos psicopedagogos, uma vez que a profissão ainda aguarda a regulamentação? Qual a identidade deste profissional? Essas, dentre outras questões apontam para necessidade da continuidade de estudos, uma vez que a psicopedagogia, no nosso país se apresenta como uma área de conhecimento relativamente nova e, portanto, com muitos desafios ainda por conquistar.

Entretanto, apesar da não regulamentação da profissão, podemos constatar a legitimação da psicopedagogia através da ampliação dos diferentes campos e modalidades da atuação psicopedagógica como em clínicas, instituições, hospitais, empresas, comunidades, e outros, que foram sendo conquistados em nosso país nos últimos anos. 
Também incentivando o crescimento e a legitimação da psicopedagogia, temos as influências externas advindas especialmente da França, onde segundo Potvin (2003), os estudos e pesquisas, estão centrados na prática psicopedagógica com alunos universitários.

No Brasil, os psicopedagogos aguardam a aprovação do projeto de lei n ${ }^{\circ}$ 3.512 de 2008, que propõe a regulamentação do exercício da atividade psicopedagógica no país. Entretanto, em alguns estados brasileiros, como no estado de São Paulo, temos, desde 2001, um elemento muito favorável impulsionando à legitimação da psicopedagogia. Ele reside na aprovação da lei n. ${ }^{\circ} 10.891$ de 2001 que autoriza o poder executivo a implantar assistência psicológica e psicopedagógica em todos os estabelecimentos de ensino básico público do estado de São Paulo com o objetivo de diagnosticar, intervir e prevenir problemas de aprendizagem. Este objetivo vem de encontro ao proposto por Andrade (2004) e Yaegashi (2013), segundo elas, o papel do psicopedagogo nas instituições de ensino deverá ser o de analisar as relações estabelecidas entre educadores, educandos e objeto de conhecimento, favorecendo a atuação, as intervenções e a construção do conhecimento, evitando assim, possíveis problemas de aprendizagem.

Ainda, no estado de São Paulo, temos a aprovação da lei municipal, $\mathrm{n}^{\circ}$ 15.719 de 2013, que dispõe sobre a implantação de assistência psicopedagógica em toda a rede municipal de ensino tendo como enfoque o educando, o educador e as instituições de ensino infantil e fundamental. Diante disso, entendemos que apesar de a psicopedagogia não se constituir em uma profissão reconhecida, ela está mais do que legitimada.

Dessa forma, frente a tantos entraves e desafios, o aluno de psicopedagogia apresenta um perfil claramente definido. O que nos leva a afirmar que ele se predispõe a refletir e a ampliar a sua formação inicial, visando conquistar subsídios que se revertam em melhorias na prática profissional.

\section{Referências}

ANDRADE, M. S.de. Rumos e diretrizes dos cursos de psicopedagogia: análise crítica do surgimento da psicopedagogia na América- Latina. Cadernos de Psicopedagogia [online]. vol. 3,nº 6, p. 70-71. ISSN 1676-1049. 2004.

ABPP. Associação Brasileira de Psicopedagogia. 2004. Disponível em: <www.abpp.com.br>. Acesso em 20 jan. 2013.

AZZI, R. G. e SADALLA, A. M .F.A. Psicologia e formação docente: desafios e conversas. São Paulo: Casa do Psicólogo. 2002

BATISTA, S.H.S. Formação de professores: discutindo o ensino da Psicologia. In AZZI, R. e SADALLA, A.M. (orgs.). Teorias implícitas na ação docente: contribuições teóricas ao desenvolvimento do professor prático-reflexivo. Campinas: Alínea, p. 21-38, 2000.

BOSSA, N. A. A psicopedagogia no Brasil: contribuições a partir da prática. Porto Alegre: Wak. 2011.

BRITTO, L.P.L. A expansão do mestrado e o novo perfil do mestrando. Revista de Estudos de Educação UNISO - Quaestio - UNISO, 1(1), p. 29-41, 1999. 
BRZEZINSKI, I. Politicas contemporâneas de formação de professores para os anos iniciais do ensino fundamental. Educação e Sociedade. Campinas-SP, v. 29, no 105, dez.2008. Disponível em: <www.scielo.br>. Acesso em: 10 jan. 2013.

CASTANHO, M.I.S. Competências na psicopedagogia: um enfoque para o novo milênio. São Paulo. Revista da Associação Brasileira de Psicopedagogia, 19(59), p. 25-30, 2002.

DALE, R. Globalização e educação: demonstrando a existência de uma cultura educacional mundial comum ou localizando uma agenda globalmente estruturada para a educação? São Paulo. Educação e Sociedade. 25(87), p. 423-460. 2004.

DEMO, P. Desafios modernos da educação. Petrópolis: Vozes. 2001.

DIAS, R.E. e LOPES, A.C. Competências na formação de professores no Brasil: o que (não) há de novo. São Paulo. Educação e Sociedade, 24(85), p. 1155-1177. 2003.

GATTI, B. A. Formação continuada de professores: a questão psicossocial. São Paulo. Cadernos de Pesquisa, n. ${ }^{\circ 119}$, p. 191-200. 2003.

GABRIEL, L.L. e YAEGASHI, S.F.R. As contribuições da psicopedagogia na ação pedagógica. In YAEGASHI, S.F.R. (org.) A psicopedagogia e suas interfaces: reflexões sobre a atuação do psicopedagogo. Curitiba: CRV, p. 23-36, 2013.

JORNAL DIARIO OFICIAL DO ESTADO DE SÃO PAULO. Lei no 10.891/2001. Publ. DOE de 21.09.2001. Disponível em: <www.imprensaoficial.com.br>. Acesso: em 20 set. 2012.

JORNAL DIARIO OFICIAL DA CIDADE DE SÃO PAULO. Lei no 15.719/2013. Publ. DOCid. De 20.04.2013. Disponível em: <www.docidadesp.imprensaoficial.com.br >. Acesso em: 03 jun. 2013.

KOLYNIAK FILHO, C. O desenvolvimento da aprendizagem na formação do sujeito. Cadernos de Psicopedagogia, 1(1), p. 92-99. 2001.

LIBÂNEO, J. C. Educação: Pedagogia e Didática. In: PIMENTA, Selma Garrido. Didática e formação de professores: percursos e perspectivas no Brasil e em Portugal. p. 77 - 129. São Paulo: Cortez. 2011.

LUQUE, D. J. Orientacion educativa e intervencion psicopedagógica. Málaga-Espanha: ALJIBE. 2006.

MASSINI, E.F.S. Psicopedagogia na escola - buscando condições para a aprendizagem significativa. São Paulo. 3a. ed. Loyola \& Unimarco, 2000.

PERES, M.R. Psicopedagogia: Aspectos históricos e desafios atuais. São Paulo. Revista de Educação, PUC-Campinas, 3(5), p. 41-45. 1998.

PERRENOUD, P. Práticas Pedagógicas, profissão docente e formação: perspectivas sociológicas. 2a. ed. Portugal: Publicações Dom Quixote Lisboa. 2000.

POTVIN, P. Pour une alliance réussie entre la pratique et la recherché en psychoéducation. Revue de Psychoéducation, 32(2), p. 211-224. 2003.

RUBINSTEIN, E. A Psicopedagogia no Brasil: uma possível leitura. 2004. Revista da Associação Brasileira de Psicopedagogia. Disponível em: <http://www.abpp.com.br>. Acesso em: 10 jan. 2013.

SCOZ, B. Psicopedagogia e realidade escolar - o problema escolar e de aprendizagem. Rio de Janeiro: Vozes, 2011.

SCOZ, B. e MENDES, M.H. A Psicopedagogia no Brasil: evolução histórica. Boletim da Associação Brasileira de Psicopedagogia, 6(13), São Paulo, p. 14-17. 1987. 
SECRETARIA DA EDUCAÇÃO DE SÃO PAULO. Lei de Diretrizes e Bases da Educação Nacional: Lei n. ${ }^{\circ}$ 9394/96. São Paulo. Coordenadora de Estudos e Normas Pedagógicas, 1996.

SERRANO, M. A formação de profissionais da educação brasileira. São Paulo. Revista da Associação Brasileira de Psicopedagogia, 19(57), p. 07-08, 2001.

VEIGA, I.P.A. Inovações e projeto político pedagógico: uma relação regulatória ou emancipatória? São Paulo, Cadernos CEDES, 23(61), p. 267-281. 2003.

VISCA, J. Psicopedagogia - novas contribuições. Rio de Janeiro: Nova Fronteira. 2003.

YAEGASHI, S.F.R. (org.). A psicopedagogia e suas interfaces: reflexões sobre a atuação do psicopedagogo. Curitiba: CRV, 2013.

* Professora Doutora da Faculdades Net Work, Faculdade de Educação. Nova Odessa, São Paulo - Brasil.

\section{Correspondência}

Maria Regina Peres - Faculdades Net Work, Faculdade de Educação. Av. Ampélio Gazzetta, n. 2445, Jd. Iglesias, CEP: 13460000 - Nova Odessa, São Paulo - Brasil.

E-mail: peresmare@hotmail.com

Recebido em 30 de março de 2013

Aprovado em 24 de agosto de 2013 